\title{
El blog Folklore de los fósiles ibéricos divulga desde 2007 las influencias del registro fósil sobre la cultura popular
}

\begin{abstract}
Folklore de los fósiles ibéricos es un blog especializado en la divulgación de los resultados de un proyecto académico, iniciado en 1995, acerca de las influencias del registro fósil ibérico sobre la cultura popular española y portuguesa, a lo largo de los últimos cuatro siglos. Durante los once años de funcionamiento ininterrumpido ha difundido a través de casi 200 entradas multitud de datos inéditos o muy poco conocidos, recogidos de innumerables fuentes, intentando informar sobre diferentes casos y aspectos relativos a la paleontología popular peninsular, estudiados con un enfoque etnopaleontológico o paleontológico-cultural.
\end{abstract}

Heraclio Astudillo Pombo | Dpto. Medi Ambient i Ciències del Sòl, Universitat de Lleida

URL de la contribución <www.iaph.es/revistaph/index.php/revistaph/article/view/4185>

Nacimiento, objetivos, funcionamiento y resultados Las publicaciones del blog Folklore de los Fósiles Ibéricos se inician el 30 de agosto de 2007 habiendo sido concebido, realizado y mantenido por el autor desde entonces. Surge de la necesidad de difundir pública y regularmente los avances de un complejo y extenso proyecto de investigación académica personal iniciado en 1995, de manera atractiva, rigurosa, comprensible y variada. La finalidad principal era atraer la atención y despertar la simpatía colaborativa de los conocedores de casos regionales de paleontología popular ${ }^{1}$. La finalidad secundaria era difundir conceptos fundamentales de reciente creación: paleontología popular, paleontología cultural ${ }^{2}$ y etnopaleontología ${ }^{3}$, así como sus diferentes manifestaciones entre investigadores en temas afines. Se aprovechaba la oportunidad de disponer de un instrumento de comunicación muy potente, fácil de gestionar y de gran utilidad como sistema alternativo, independiente y autogestionado de publicación.

La difusión pública por Internet de los primeros planteamientos teóricos, resultados o conclusiones y propuestas iniciales se inicia cuando ya se disponía de abundantes casos localizados y estudiados, con infinidad de datos recopilados que confirmaban predicciones, facilitaban establecer tipologías, validaban hipótesis iniciales y permitían construir un marco general de referencia. El idioma utilizado ha sido el español por ser la Península Ibérica el territorio estudiado y por disponer

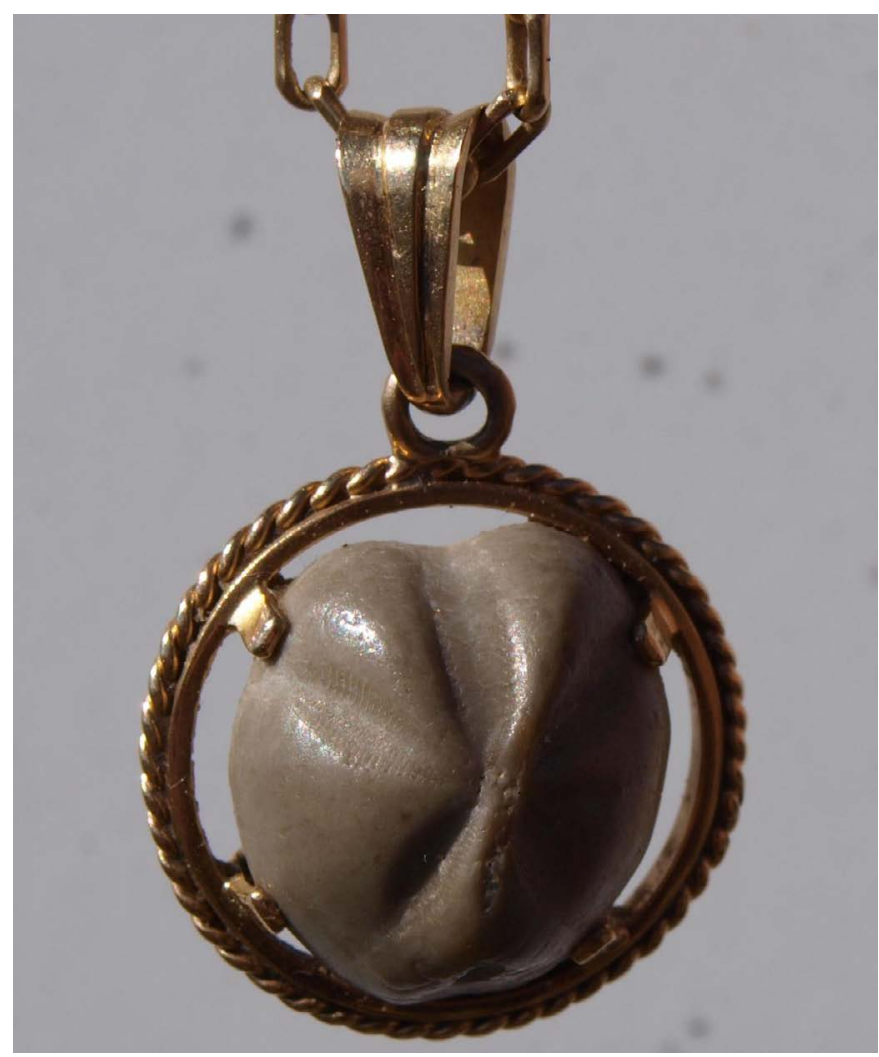

Ejemplo de uso apotropáico: peculiar joya religiosa elaborada hacia 1998 por un joyero de Soria, con un ejemplar de erizo marino fósil (Mecaster scutiger) del Cretácico, recogido por una devota en las inmediaciones de la ermita de la Virgen de Inodejo, en Las Fraguas (Soria). En montura de plata sobredorada para ser llevado colgando del cuello. La propietaria es una señora mayor de Nódalo (Soria). Son llamados popularmente piedrecitas de la Virgen, tradicionalmente se le atribuyeron origen prodigioso y milagrosas virtudes protectoras por lo que se recogían el día de la romería patronal | foto J. Soria, 2012 
el blog de un traductor a cualquier otro idioma al que podían optar los consultantes extranjeros que no dominasen nuestra lengua común. Durante los 11 años de funcionamiento ininterrumpido, ha difundido de forma permanente y regular multitud de datos inéditos o muy poco conocidos, recogidos de innumerables fuentes, intentando informar sobre diferentes casos y aspectos relativos a la paleontología popular peninsular, estudiados con un enfoque etnopaleontológico o paleontológico-cultural. Se han publicado 194 entradas, todas originales de extensión considerable, distribuidas en 26 secciones temáticas, con un éxito muy variable de visitantes, entre 109 y 6874 por entrada, siendo la gran mayoría peninsulares o hispanoamericanos.

En cuanto a los fracasos reseñables, destaca la incapacidad del blog para desencadenar la empatía colaborativa. No ha servido para captar datos ni asociar expertos con los que formar grupos regionales colaboradores. Ha servido para dar a conocer conceptos como paleontología cultural y etnopaleontología y diversas particularidades de la paleontología popular ibérica, siendo citado y elogiado como referencia por algunos estudiosos y publicaciones, nacionales y extranjeras. La ineficacia captadora y agregadora del blog se mitigó mediante centenares de mensajes de correo electrónico, dirigidos a informantes potenciales, solicitando colaboraciones informativas muy específicas y poco dificultosas. Aunque su efectividad ha sido baja, la mayoría de datos recibidos tienen gran valor testimonial por ser inéditos. Además las aportaciones colaborativas de algunos contactados han resultado cruciales para el desarrollo regional de la investigación y dotar de contenido algunas entradas del blog.

Conseguir la formación de equipos de colaboradores regionales hubiera sido un gran logro, pues se hubieran explorado más intensamente y conocido más profundamente las diversas realidades etnopaleontológicas o paleontológico-culturales regionales. Además hubiera facilitado la participación en más eventos académicos regionales y la multiplicación de las publicaciones científicas, consiguiéndose una mayor difusión de las particularidades de la paleontología popular regional y de las utilidades de la etnopaleontología y de la paleontología cultural como instrumentos de estudio de la rea-

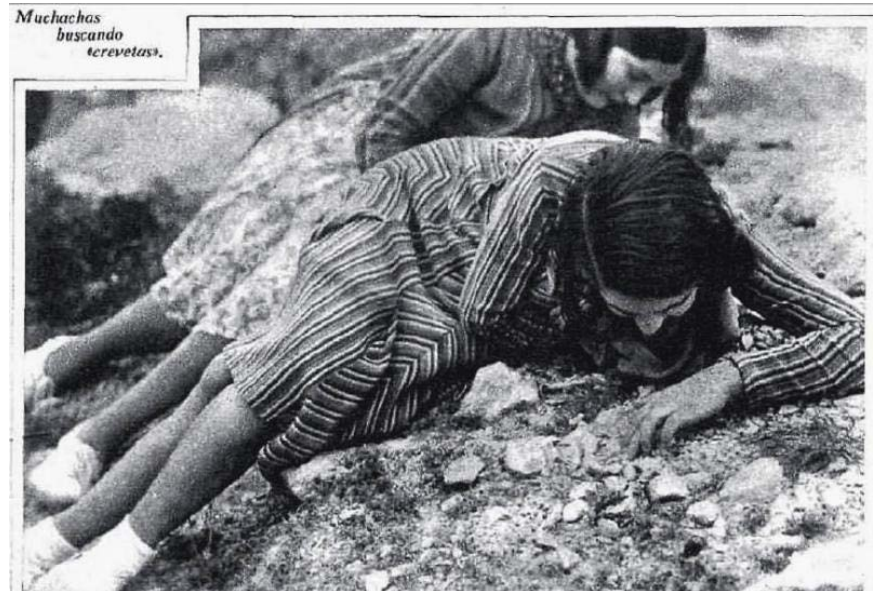

Dos muchachas tortosinas en edad casadera buscando estrellitas de la Virgen en las inmediaciones de la ermita de Ntra. Sra. de la Providencia (Tortosa), durante la romería de la fiesta patronal de 1933. Tradicionalmente a estos fósiles se le atribuyeron origen prodigioso y múltiples virtudes protectoras y milagrosas, entre otras muchas librar a las mujeres de la soltería, de dolores menstruales y de favorecer la concepción, el embarazo y el parto. Se trata de minúsculas piezas articulares de forma estrellada, desprendidas post mortem, del tallo peduncular de unos pequeños crinoideos marinos de la especie Pentacrinus neocomiensis, del Cretácico | fuente ARENAS, 1933: 7-10

lidad social y como herramientas auxiliares para otras disciplinas indirectamente relacionadas con el registro fósil (ASTUDILLO, 2010: 295). La validez de todos estos hipotéticos planteamientos organizativos se ha podido demostrar plenamente para el caso de las Baleares.

\section{Vinculaciones y usos de algunos fósiles ibéricos}

De resultas de la investigación sobre paleontología popular ibérica realizada por el autor, durante los últimos 12 años se han dado a conocer, a través del blog y de otras publicaciones, multitud de influencias paleontológicas sobre la cultura popular ibérica, que se han puesto de manifiesto implícitamente por decenas de creencias y prácticas supersticiosas, relatos legendarios y costumbres tradicionales sorprendentes, asociadas a la religiosidad popular y a determinados santuarios rurales, españoles o portugueses.

En tiempos pasados, en ciertas localidades, se relacionaron míticamente con el rayo determinados tipos de fósiles, algunos de estos mismos fósiles se vincularon con personajes sagrados como Santiago Apóstol, Dios, la Trinidad y algunos santos, o con las brujas o el Diablo. En otros casos, ciertos tipos de fósiles se relacionaron legendariamente con Jesucristo, el Espíritu Santo, 


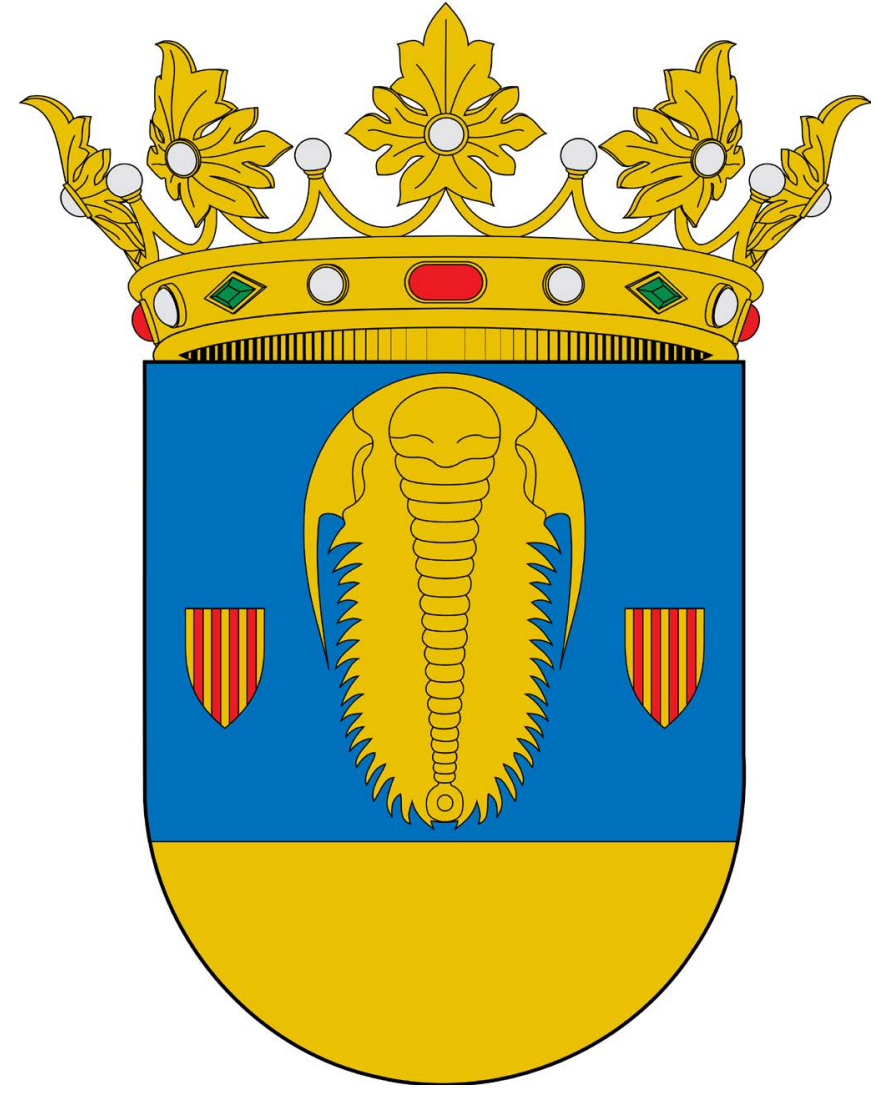

Ejemplo de uso heráldico: actual escudo municipal de Murero (Zaragoza), adoptado desde el 19 de mayo 1998 como reconocimiento a la fama y beneficios económicos reportados por el estudio y difusión de un yacimiento excepcional de trilobites del Cámbrico en la rambla de Valdemiedes. El yacimiento estrictamente paleontológico (sin restos arqueológicos asociados) fue declarado bien de interés cultural en la categoría de sitio histórico el 8 de julio de 1997. Se eligió como emblema heráldico principal la representación de un ejemplar de Paradoxides mureroensis, la especie descrita por vez primera en Murero | fuente Wikipedia (Anenja, Taller de Heráldica y Vexilología in the Spanish Wikipedia)

la Virgen María o diversos santos, o con moros, judíos, paganos o herejes. También que los grandes huesos fósiles hallados se consideraron auténticas reliquias de los gigantes bíblicos y testimonios del Diluvio. Algunos fósiles por su vinculación mítica sagrada, fueron usados como amuleto o medicamento. Las marcas de pisadas fosilizadas de dinosaurios y otros animales prehistóricos, se relacionaron legendariamente con diversos personajes sagrados o ciertos animales fabulosos.

También se ha podido constatar y publicar que la localización geográfica o la forma de ciertos tipos de fósiles motivó e inspiró la creación del léxico local con el que se los nombra en las diversas lenguas vernáculas regionales. Se han descubierto y recopilado centenares de nombres vulgares de fósiles, publicando decenas de ellos en el blog. Además forma y localización motivaron la invención de relatos legendarios para justificar su presencia en un lugar y su forma peculiar. Así mismo los nombres vulgares de algunos tipos de fósiles aparecen integrados en la toponimia local, indicando allí su presencia y dando nombre a elementos geográficos naturales y artificiales. Se han recopilado centenares de nombres de lugar españoles asociados a ciertos tipos de fósiles, dándose a conocer decenas de ellos en el blog ${ }^{4}$.

También se ha publicado que en tiempos recientes ciertos tipos de fósiles sirvieron para promocionar el turismo en lugares en los que son el principal atractivo, motivando la revaloración del patrimonio natural y activando la economía local; que se utilizaron como emblema en la promoción de ciertos vinos y licores o que inspiraron la creación de productos comerciales relacionados con la hostelería, la alimentación, la joyería, la ropa y complementos o la juguetería; que incluso se utilizaron como ornamentación en la arquitectura popular. Algunos tipos de fósiles emblemáticos han sido convertidos en icono heráldico ${ }^{5}$, numismático o filatélico o en logotipo corporativo institucional, empresarial o asociativo, además de haber servido para poner nombres a empresas, asociaciones y rutas culturales o clubes y competiciones deportivas o dar título y contenido a poemas y canciones.

\section{NOTAS}

1. La paleontología popular es la base de partida para toda investigación etnopaleontológica o cultural-paleontológica. Es el conjunto de creencias, conocimientos, actividades y creaciones materiales e inmateriales relacionadas con determinados tipos de restos fósiles presentes en el entorno, surgidas con finalidades interpretativas o manipulativas, sustentadas en la tradición o la intuición pero nunca en la ciencia. Constituye una parte del conjunto de concepciones y prácticas características e identitarias de los individuos de una comunidad particular, en un lugar y momento histórico concretos. 
2. La paleontología cultural es una nueva área académica de estudio de la realidad social, desde una perspectiva no étnica, recientemente definida, con los correspondientes objetivos y procedimientos asociados, válidos para el estudio de la paleontología popular de un cierto lugar y momento. Estudia algunos aspectos socioculturales muy generales y modernos, de ámbito regional, continental o intercontinental, relacionados con la asimilación de ciertos tipos de restos fósiles. Sintéticamente se puede decir que la paleontología cultural estudia las generalidades más extendidas, más deslocalizadas o globalizadas de la paleontología popular que son propias de muchas sociedades culturalmente heterogéneas y de distribución geográfica muy extensa, como la asimilación emblemática del registro fósil por la heráldica, la numismática, las artes, etc. en la Europa o Norteamérica contemporáneas.

3. La etnopaleontología es una nueva área académica de estudio de la realidad social desde una perspectiva étnica, en localidades fosilíferas, recientemente defini$\mathrm{da}$, con los correspondientes objetivos y procedimientos asociados, válidos para el estudio de la Paleontología popular de un cierto lugar y momento. Estudia algunos aspectos socioculturales muy particulares, propios de una pequeña comunidad humana, relacionados con ciertos tipos de restos fósiles existentes en el territorio de un municipio, comarca o comunidad autónoma, por causas geológicas o mercantiles. Sintéticamente: la Etnopaleontología estudia las particularidades de la Paleontología popular, menos extendidas o más localizadas, propias de unas pocas comunidades, muy afines culturalmente, coetáneas y distribuidas en una región geográfica pequeña. Por ejemplo. la asimilación religiosa de un cierto tipo de crinoideos fósiles por la cultura popular de la población de Tortosa y su comarca durante los siglos XVIII-XX.

4. En el caso particular de Andalucía, hasta el momento actual se llevan recogidos veinticinco nombres vulgares de fósiles y cuarenta y siete "paleontotopónimos", algunos de los cuales aparecen en el blog.

5. Consultar en el blog Glossopetrae, los casos ibéricos de Canelas-Arouca (Portugal), Murero (Zaragoza), Kor- tezubi (Vizcaya) y Orís, (Barcelona) en sección temática: El registro fósil en la heráldica municipal europea.

\section{BIBLIOGRAFÍA}

- ARENAS, P. (1933) La Virgen de las estrellas. Estampa. Revista gráfica, n. ${ }^{\circ} 281,27$ de mayo 1933, pp. 7-10

- AStudillo POMBO, H. (2010) Paleontología cultural y Etnopaleontología. Dos nuevos enfoques sobre el registro fósil. Enseñanza de las Ciencias de la Tierra, vol. 18, n. ${ }^{\circ}$, pp. 284-297 